\begin{tabular}{|c|c|c|c|c|c|c|}
\hline \multirow{4}{*}{ Impact Factor: } & ISRA (India) & $=3.117$ & SIS (USA) & $=0.912$ & ICV (Poland) & $=6.630$ \\
\hline & ISI (Dubai, UAE & $=0.829$ & РИНЦ (Russia & $=0.156$ & PIF (India) & $=1.940$ \\
\hline & GIF (Australia) & $=0.564$ & ESJI (KZ) & $=8.716$ & IBI (India) & $=4.260$ \\
\hline & JIF & $=1.500$ & SJIF (Morocco & $=\mathbf{5 . 6 6 7}$ & OAJI (USA) & $=0.350$ \\
\hline
\end{tabular}

\section{SOI: 1.1/TAS DOI: 10.15863/TAS International Scientific Journal Theoretical \& Applied Science}

\author{
p-ISSN: 2308-4944 (print) e-ISSN: 2409-0085 (online) \\ Year: $2019 \quad$ Issue: $04 \quad$ Volume: 72
}

Published: $27.04 .2019 \quad$ http://T-Science.org
QR - Issue
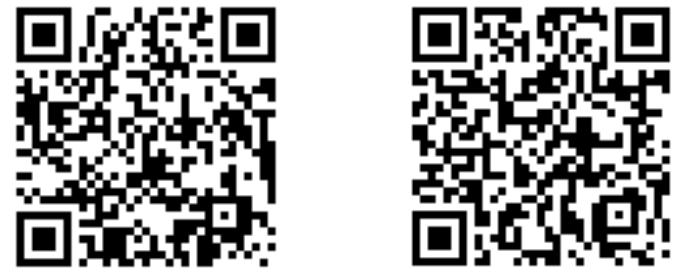

Sanobar Panjievna Tulaganova

Institute of Uzbek Language, Literature and Folklore of the Academy of Sciences, Tashkent, Uzbekistan

Doctor of filoloji

s.tulaganova@mail.ru

\title{
BIOGRAPHICAL APPROACH AS A SCIENTIFIC AND THEORETICAL PROBLEM
}

\begin{abstract}
There are few authors in the world literature who can attract attention of the reader. Especially, gaining of authority in art and literature promotes changes and development of moral thinking of the nation. It can be seen in literature and life of people of Orient and West. The article analyzes the life of the first Uzbek writer Abdullah Kodiri on a biographical basis. The biographical method is interpreted as the main method of studying creativity. For the first time in Uzbek literary criticism, the life of Kadiri was studied by biographical methods. Father Kodirmuhammad plays a special role in the formation of the writer. Grandfather Kodirmuhammad bobo is a living witness of historical events in the novels and played an important role in the artistic expression of reality.

Key words: biographical method, writer, Uzbek novel, Abdullah Kodiriy, Kadir Muhammad bobo.

Language: Russian

Citation: Tulaganova, S. P. (2019). Biographical approach as a scientific and theoretical problem. ISJ Theoretical \& Applied Science, 04 (72), 377-381.

Soi: http://s-o-i.org/1.1/TAS-04-72-48 Doi: crossef https://dx.doi.org/10.15863/TAS.2019.04.72.48

\section{БИОГРАФИЧЕСКИЙ ПОДХОД КАК НАУЧНО-ТЕОРЕТИЧЕСКАЯ ПРОБЛЕМА}

Аннотация: В мировой литературоведении был разработан научно-теоретического метода. $B$ статье, биографический метод упомянут как основной методикой изучения творческой личности, а также была анализирована, этим методом, жизнь первого узбекского романиста А.Кадыри. Совершенствование писателя заслуги его отца Кадырмухаммад бобо имели особое значение. В романах писателя Кадырмухаммад бобо был участником в исторических войнах, а также живым свидетелем событии сыграл большую роль в интерпретачии реальных явлениях.
\end{abstract}

Ключевые слова: Биографический метод, творческая личность, писатель, узбекский роман, Абдулла Кодирий, Кадыр Мухаммад бобо.

\section{Введение}

Исследование биографии писателя в тесной связи с его творчеством позволяет решать многие проблемы. Очень часто мы изучаем, анализируем, обсуждаем произведения различных писателей, оставляя без внимания его личность и жизнь. Личность художника изучалась в мировой литературе как научная проблема, разрабатывались его собственные принципы. Изучение личность художника различными методами: биографическим, психологическим, социальным, герменевтическим, сравнительным и аналитическим методами помогает повысить роль и значимость работы. Биографический метод - это способ восприятия, анализа и оценки художественной литературы, при котором биография и личность писателя становится определяющим моментом творчества. Любое произведение является оригинальным и историческим. Творчество - это явление, объединяющее не только художественные, но и духовные, культурные, философские, исторические и религиозные корни.

\section{Материалы и методы}

В настоящее время усилилось внимание изучению новой узбекской литературы начала XX века, её духовно-культурного развития, многогранной и разнообразной природы, а также истоков социально-политических, литературных и психологических факторов, породивших новую узбекскую прозу. При осмыслении 


\begin{tabular}{|c|c|c|c|c|c|c|}
\hline \multirow{4}{*}{ Impact Factor: } & ISRA (India) & $=3.117$ & SIS (USA) & $=0.912$ & ICV (Poland) & $=6.630$ \\
\hline & ISI (Dubai, UAE & $=0.829$ & РИНЦ (Russia & $=0.156$ & PIF (India) & $=1.940$ \\
\hline & GIF (Australia) & $=0.564$ & ESJI (KZ) & $=8.716$ & IBI (India) & $=4.260$ \\
\hline & JIF & $=1.500$ & SJIF (Morocco & $=\mathbf{5 . 6 6 7}$ & OAJI (USA) & $=0.350$ \\
\hline
\end{tabular}

художественного произведения как культурное, историческое, социальное явление, необходимо исследование его автора не только как литературно-эстетическую проблему, но и в разрезе философских, социальных, психологических проблем. В мировом литературоведении проблема творческого лица и художественного героя изучается в непосредственной связи с явлением творческой гармонии. На сегодняшнее время актуальным является изучение истории национальной литературы, художественного наследия в контексте мирового литературоведения с помощью объективных, передовых научнометодологических методов.

Наследственные особенности творческого лица являются ведущим условием, при этом творческое лицо повторяет на примере себя качественные признаки своих предков, долгое время хранит в себе историческую родословную историю. Доказано, что в самые сложные моменты жизни, при чрезвычайных обстоятельствах проявляют себя генеалогические особенности. Желает того или нет, подсознательно или неосознанно человек наследует наследие предков. Изучение творческого лица в неразрывной связи с наследственными признаками очень полезно для познания характера его природы и характера героя произведения.

Как известно, среди предков великих людей могут быть одаренные люди и даже гении. Амир Темур был признан гениальным человеком в политике, социальной активности. Его предки и потомки в этой отрасли превосходили других. Согласно сведениям исторических источников темуридские царевичи обладали большим творческим потенциалом и незаурядным поэтическим талантом. Гениальные люди, оставившие след в истории - Улугбек Мирзо, Бабур Мирзо, Хусайн Мирзо были потомками Амир Темура. С учетом того, что подавляющее большинство из 21 одного темуридского царевича, включенного в антологию Алишера Навои, были авторами диванов, можно смело говорить о роли генетического фактора в творчестве.

К сожалению, определение биографии как “жанра жизнеописания” недостаточно, поскольку за дефиницию мы принимаем буквальный перевод слова. Еще недавно считалась, что биография “дает картину жизни человека, развитие его личности в связи с общественными обстоятельствами эпохи” [10]. Теперь же, согласно “Литературной энциклопедии терминов и понятий”, биография "предполагает художественное или научное осмысление истории жизни личности, нацеленное на поиск и выявление истоков общественно значимой деятельности человека в его индивидуальном биографическом опыте" [5].

Ибо, как утверждает основатель биографического метода Сент- Бёв: «Решающей субстанцией литературного творчества является конкретная, индивидуальная личность самого творца. Произведение - это «заговорившая личность», а личность - это душевный мир художника, обретший адекватную словесную плоть» [9]. Глубокие

переживания и страдания, перенесенные творческим лицом, непременно оставляют свой след в каждом его произведении. Автор - это тоже живая плоть, в которой чувствуется влияние генов. Писателя понять нелегко, он не раскрывает своих секретов. Юнг считает, что художественное творчество - это духовная деятельность. “Тайна творческого начала, так же как и тайна свободы воли, есть проблема трансцендентная, которую психология может описать, но не разрешить. Равным образом и творческая личность - это загадка, к которой можно, правда, приискивать отгадку при посредстве множества разных способов, но всегда безуспешно [8]. В свое время Ю Лотман предупреждал, что “смешение этих двух типов книг - биографии автора и анализа им созданных произведений - редко приводит к удаче"'[6].

Узбекский писатель Назар Эшанкул пишет о творчестве «Творчество - это чувство величия и понимания силы Господа». [11]. Автор описывает творение как божественное событие, а художник является представителем духовного мира. Проблема личности очень важна как для настоящего и будущего литературы, так и для судьбы нации. Проблема личности художника изучается в восточно-мусульманском мире другом ракурсе. Отличается от взглядов западных ученых.

Человек является как социальным, так и биологическим созданием. По утверждению психологов, ребенок набирает основной запас слов до пяти лет, а на протяжении оставшейся жизни использует этот лексический багаж и дополняет его. Не зря говорят «Yoshligingda olganing toshga yozganing», («Знания, полученные в детстве, прочнее камня»), В силу этого основным в воспитании ребенка считается семейный очаг и окружающая его среда. Няня Пушкина, дедушка Айбека, бабушки Хамида Алимджана и Чингиз Айтматова сыграли определенную роль в раскрытии таланта будущих поэтов и писателей, восполнении их духовного «багажа», формировании их мировоззрения.

Мы анализировали историю написания первых узбекских романов относительно семейного окружения писателя. Генетические и наследственные особенности писателя изучаются в психогенетике. Влияние наследственного 


\begin{tabular}{|c|c|c|c|c|c|c|}
\hline \multirow{4}{*}{ Impact Factor: } & ISRA (India) & $=3.117$ & SIS (USA) & $=0.912$ & ICV (Poland) & $=6.630$ \\
\hline & ISI (Dubai, UAE & $=0.829$ & РИНЦ (Russia) & $=0.156$ & PIF (India) & $=1.940$ \\
\hline & GIF (Australia) & $=0.564$ & ESJI (KZ) & $=8.716$ & IBI (India) & $=4.260$ \\
\hline & JIF & $=1.500$ & SJIF (Morocco & $=5.667$ & OAJI (USA) & $=0.350$ \\
\hline
\end{tabular}

фактора на творчестве очень велико. Мы решили исследовать эту проблему на примере жизни и семейной обстановки Абдуллы Кадыри, поскольку несомненно, что за великим феноменом Абдуллы Кадыри скрываются труды близких ему людей. Судьбе было угодно, чтобы в молодые даже по европейским стандартам годы, а точнее в 24 лет, Абдуллы Кадыри создал первый узбекский роман - произведение нового в начале XX века направления в узбекской литературе, которое не могло появиться на пустом месте. Этот процесс имел несколько источников. В источниках написано, что писатель был загадочным и скрытым, очень религиозным человекам. Учитель писателя в источниках не упоминается. Ответы на вопросы, кто был первым учителем Абдуллы Кадыри, на какой почве появился первый узбекский роман и почему его интересовала историческая тема, мы постараемся найти исходя из семейного окружения писателя.

До сих пор исследователи обращали внимание на социальные особенности семьи писателя. Сотти Хусайин утверждал, что Абдуллы Кадыри был из «мелкой буржуазии», а Иззат Султан писал, что он - «сын торговца». В книге «Чудо Кадыри» У.Норматов отметил, что писатель был «сыном безызвестного, простого старика Кодир бобо» [5], а в конце книги в статье «Поклон отцу», уделяя особое внимание личности отца писателя, утверждал, что последний был «золотым звеном» в совершенствовании писателя. Подобные взгляды являются первыми набросками биографии писателя. Чтобы не повторять утверждения наших наставников, мы хотим решить вопрос о роли семьи в формировании творческой личности и процессе превращения жизненной правды в художественную действительность на материале произведений Х.Кадыри «Otamdan xotira» («Об отце»), А.Кадыри «Диёри бакр», Ш.Кадыри «37-xonadon» («37-й дом»).

Анализ текста в литературоведении может внести ясность в решение многих проблем и раскрыть истинные причины событий или явлений. Вот что пишет Кадыри в 1926 году в судебной речи: «...сначала я не совсем понял — в богатой семье я родился или бедной» [4.84c]. Не сложно понять, что писатель не может признать свою состоятельность или бедность. Не стоит забывать, в каких условиях и при каких требованиях было написано данное признание.

Кадырмухаммад Хаджимухаммад угли был физически крепким, энергичным, грамотным человеком, в молодые годы служил при дворе ханов и беков, спустя годы после захвата Средней Азии Российской империей в 1865 году открывает в Старом городе небольшую бакалейную лавку. По торговым делам ему довелось побывать в далеких странах, например в Карачи [1], до глубокой старости ему приходилось заниматься земледелием и садоводством, чтобы содержать семью. У Кадырмухаммада бобо было трое сыновей, после старшего Рахимберди (1879) один за другим умирают 12 детей. Абдулла Кадыри (1894) родился, когда отцу было около 72-73 лет. Его мать Жосиятбиби говорила, что Абдуллу она получила после того, как похоронила двенадцать детей. Третий сын Кудратилла (1897) родился, когда Кадырмухаммаду было 76-77 лет. Несмотря на то что деньги на жизнь доставались с трудом, отец освобождал детей от работы, если видел их желание учиться. В воспоминаниях Абдулла Кадыри пишет, что его братьев частенько наказывали за пренебрежительное отношение к учебе, тогда как он никогда не получал выговора [4.82 c]. Абдулла любил школу, был очень смышлёным, старательным, но молчаливым ребенком, любил одиночество. Естественно, что Абди (так его называл отец) был непосредственным участником бесед отца с его старыми друзьями, которые приходили его навещать и многое рассказывали, вспоминая былое.

Дедушка по материнской линии Азиз суфи служил правителю Ташкента Азизбеку, а со старившись, стал муэдзином в местной мечети. Не исключено, что Абдулла частенько был свидетелем бесед между Кадырмухаммадом и Азизбаем. Под влиянием этих бесед писатель постепенно в уме формировал предварительные наброски проекта будущего романа, создавал первые штрихи разбросанных эпизодов.

Кадырмухаммад бобо был хорошим знатоком национальных мотивов и любил рассказывать исторические легенды, предания, любовные, приключенческие рассказы. Все сыновья с интересом слушали эти рассказы, но только Абдулла осмелился объединить эти рассказы единой идеей и вернуть их своему народу в новом виде, превратив в художественное произведение. Сделать это ему позволили его талант и сила рассказчика, унаследованная им от своих предков. «Гений - это владыка, собирающий вокруг себя своих подданных» [3]. Отвага, трудолюбие, требовательность Кодирбобо перешли к его сыну Абдулле. Айбек пишет: «Он (Абдулла Кадыри) был настолько трудолюбивым, что не каждому творческому лицу дается такая способность». Х.Кадыри подтверждает слова Айбека: «...не будет преувеличением, если скажу, что он писал настолько быстро, что его темп можно сравнить с темпом стенографиста» [4,c.84]. Кодирбобо скончался в 1924 году, об этом было напечатано на страницах газеты «Туркистон», где было отмечено, что мать Кодирбобо умерла в 117 , а брат в 106 лет.

Вот что пишет автор об отце в журнале «Инкилоб» («Революция») в 1922 году: «Отец 


\begin{tabular}{|c|c|c|c|c|c|c|}
\hline \multirow{4}{*}{ Impact Factor: } & ISRA (India) & $=3.117$ & SIS (USA) & $=0.912$ & ICV (Poland) & $=6.630$ \\
\hline & ISI (Dubai, UAE & $=0.829$ & РИНЦ (Russia & $=0.156$ & PIF (India) & $=1.940$ \\
\hline & GIF (Australia) & $=0.564$ & ESJI (KZ) & $=8.716$ & IBI (India) & $=4.260$ \\
\hline & JIF & $=1.500$ & SJIF (Morocco & $=\mathbf{5 . 6 6 7}$ & OAJI (USA) & $=0.350$ \\
\hline
\end{tabular}

родился в 1242 году по старому летосчислению, в 1823 по новому, в Ташкенте. Жил во времена правления туркестанских ханов Шералихана, Худаярхана, Маллахана и ташкентских беков Мухаммеда Шарифа, Салимсакбека, Азизбека, Нормухаммеда кушбеги, Каноат шаха, Маллахана, сопровождал в Кашгар известного Якуббека из Пскента. Таким образом на протяжении сорока лет был свидетелем правления мусульманских ханов, пятидесяти лет правителей Царской России и вот последних пяти лет - правления трудового народа» [4,110 c].

В детстве отец мой, более века живший при правлении ханов и многое повидавший на своем веку, рассказывал нам интересные и забавные случаи из жизни. Эти воспоминания пробудили во мне интерес к истории. Затем, ознакомившись со многими источниками по истории тех времен, у меня появилось желание создать произведение в жанре западной литературы. Исторические события будто кипели в моей голове, они не давали мне покоя, однако я не мог представить, как можно нанизать все эти истории на одну; нить и изложить все на бумаге:

В один прекрасный день из города в наш сад к отцу приехал один старик. Отцу в то время было около ста, а гость выглядел на 5-10 лет моложе. Отец спросил у гостя: «Сколько у вас детей от жены в Андижане?», их беседы я понял, что это из Ташкента, у него есть семья, дети. Однако в молодые годы торговым делам он уехал в Андижан, долго жил там, женился, обзавелся детьми, состарившись, верится к себе на родину: Эта обыкновенная история гостя будто дала решение моей проблемы и набросала предварительные штрихи моей будущей книги» $[4,123 \mathrm{c}]$.

Этот фрагмент, который помог писателю найти определенную форму его разбросанным мыслям, может многое прояснить в истории создания произведения «Минувшие дни».

По мнению Бахтина, мир эпоса мир “предков и дедов”, “лидеров” и “лучших”. Исполнитель и слушатель эпоса вступая в связь с людьми прошлого, с событиями, произшедшими с ними, рассматривает его как идеал, сравнивает его с современностью, людьми своей эпохи. Ибо, по мнению современного человека его эпоха не совершенна, а будущее - абстрактно. Лишь прошлое совершенно, достойно поисков идеала. [2]

Согласно этой теории, историческую эпоху времени Кадырмухаммада бобо Кадыри помещает в художественную форму на основе единой системы. И в эпосе живёт Алп, создаёт события, а его потомки слагает дастаны об Алпе. Кадыри систематизацию процесса на основе художественных законов выполняет на высоком уровне с точки зрения творческого потенциала.
Чтение множества исторических книг, знание арабского, турецкого, персидского, русского языков, знакомство с исламской философией, изучение различных литературных течений, знание в совершенстве народного языка, неустанный труд, потребность в передаче осмысленных вещей заложили фундамент для создания известного произведения. Появилась модель авторских идей - роман, учитывающий уровень грамотности народа и его вкус, систематизировавший все события, подчинивший их единой цели.

Основным рассказчиком следующего романа писателя был Кадырмухаммад бобо, он непосредственно участвовал в процессе помолвки Анвара и Раъно и имел дружеские отношения с Анваром. В «Воспоминаниях об отце» писатель пишет: «Я спросил у отца: События в романе «Скорпион из алтаря» на самом деле вам рассказал Кодир бобо, как вы пишете в прологе романа?»[4,120 c].

Потомки ханов и подстрекатели-беки ради трона боролись в междоусобных войнах и проливали столько крови, что в результате царские войска один за другим захватили города Ферганской долины, а ханы не обращали на это внимания; мелкие причины привели к большим потерям. Чувство народного горя, потери независимости Абдулла Кадыри передал своими произведениями.

Не следует забывать, что немаловажную роль в становлении человека занимают наследственные признаки и являются ведущим фактором в познании вселенной. Но в реализации способностей следует отметить не только психогенетические факторы, но и ряд других факторов.

Абдулла Кадыри, бесспорно, изучил приемы повествования западных писателей - Толстого, Достоевского, Чехова, Тагора, Зайдона - и различные литературные течения. Однако мы предполагаем, что среди учителей Кадыри наряду с представителями классического философского наследия - Руми, Физули, следует называть и его отца.

Писатель, предпочитавший писать об «услышанных им вещах, в которые он верил сам», искал особый стиль, способный точно передать народное горе, и нашел прием, соответствующий вкусу и уровню народа. При изучении социального положения семьи писателя и его биографии исследователи часто не обращают внимания на личность его родителей, их цели, мечты, мировоззрение. Изучение личности писателя в тесной связи с его произведениями способствует развитию литературоведения и может привести к обобщающим выводам.

Кадырмухаммад, превратившийся в живую историю, воспитал в сыне любовь и стремление к 


\begin{tabular}{|c|c|c|c|c|c|c|}
\hline \multirow{4}{*}{ Impact Factor: } & ISRA (India) & $=3.117$ & SIS (USA) & $=0.912$ & ICV (Poland) & $=6.630$ \\
\hline & ISI (Dubai, UAE & $=0.829$ & РИНЦ (Russia & $=0.156$ & PIF (India) & $=1.940$ \\
\hline & GIF (Australia) & $=0.564$ & ESJI (KZ) & $=8.716$ & IBI (India) & $=4.260$ \\
\hline & JIF & $=1.500$ & SJIF (Morocco & $=\mathbf{5 . 6 6 7}$ & OAJI (USA) & $=0.350$ \\
\hline
\end{tabular}

творчеству. Разумный и рассудительный малыш «Абди», произведения которого способны прославить узбекский народ на весь мир, получил сначала свои знания в народной школе. Такие осведомленные люди как Кадырмухаммад бобо смогли вложить в его душу загадочные коды этой жизни, которые, воплотившись в качестве специальных программ и художественной концепции в его произведениях, смогли раскрыть внутренний мир самого автора. Родители, считающиеся старшими наставниками школы жизни, скрывающиеся за каждым великим феноменом, воспитывают народ подобно преданному делу учителю. В формировании мировоззрения, образа мышления и созидания мира Абдуллы Кадыри его первым учителем был отец, непосредственно влиявший на создание его романов, что и побудило нас обратиться к этой проблеме.

\section{Заключение}

личность художника отражает философское понятие, как генеалогия, наследственность, религия и нация;

биографический метод является важным способом для обучения творчеству;

психобиографический метод подчеркивает психологию писателя и привлекает внимание к решению проблемы;

психогенетические элементы имеют особое значение в формировании творческой личности; психогенетические категории играют важную роль в развитии романного мышления; отец писателя Кадырмухаммад ота - великий рассказчик истории нации.

\section{References:}

1. Abdullaev, M. (2012). Utkanlar edi. (p.67). Toshkent, Press-Liz.

2. Zhurakulov, U. (2015). Mikhail Bakhtin kashfietlari. Nazariy poetika masalalari. (p.84). Toshkent: F.Fulom nashrieti.

3. (1987). Sost., obshchaya redaktsiya G.K.Kosikova. Zarubezhnaya estetika i teoriy literatury KhKh vv. Traktaty, stat'i, esse. (p.47). Moscow: Izd.MGU.

4. Kodiriy, K. (2005). Otamdan khotira. (p.12). Toshkent: Yangi asr avlodi.

5. (1987). Literaturnyy entsiklopedicheskiy slovar' / Pod red. V.M.Kozhevnikova, P.A Nikolaeva (Eds.). (p.54). Moscow: Sovetskaya entsiklopediya.
6. Lotman, Y. M. (1985). Biografiya - zhivoe litso. Novyy mir, № 2, p.28.

7. Normatov, U. (2010). Kodiriy mu"zhizasi. (p.11). Toshkent, Uzbekiston.

8. (2000). Samosoznanie kul'tury i iskusstva KhKh veka. Zapadnaya Evropa i SShA. (pp.114-130). Moscow: Unversitetskaya kniga.

9. Sent-Bev, S. O. (1970). Literaturnye portrety. (p.48). Moscow: Khudozhestvennaya literatura.

10. Sobolevskaya, O. V. (2003). Biografiya. Literaturnaya entsiklopediya terminov $i$ ponyatiy. Pod.red. A.N.Nikolyukina (Eds.). (p.90). Moscow: Intelvak.

11. Eshonkul, N. (2014). Mendan mengacha. (p.206). Toshkent: Akademnashr. 